\title{
IDENTIFIKASI JENIS ALGA KORALIN DI PULAU SALAWATI, WAIGEO BARAT KEPULAUAN RAJA AMPAT DAN PANTAI MALALAYANG KOTA MANADO
}

\author{
(Identification of Coraline Alga from Salawati Island and West Waigeo, Raja Ampat \\ Archipelago and Malalayang Coast, Manado)
}

\section{Biondi Tampanguma ${ }^{1 \star}$, Grevo S. Gerung ${ }^{1}$, Calvyn F. A. Sondak ${ }^{1}$, Billy Th. Wagey ${ }^{1}$, Indri S. Manembu ${ }^{1}$, Khristin I. F. Kondoy ${ }^{2}$}

1. Program Studi Ilmu Kelautan, Fakultas Perikanan dan IImu Kelautan, Universitas Sam Ratulangi, Manado.

2. Program Studi Manajemen Sumberdaya Perairan, Fakultas Perikanan dan IImu Kelautan, Universitas Sam Ratulangi, Manado.

*e-mail : biondi.tampanguma@gmail.com

Coraline alga is one of seaweeds group that classified into Rhodophyta Division, Florideocphyceae class, ordo Cryptonemiales and family Corralinaceae. Based on its morphology (external appearance) Coralinaceae family was divided into articulated/geniculated corraline algae and non-articulated/non-geniculated corraline algae. The objectives of this study are to identify and describe the morphology of these algae. Sampling was done in Raja Ampat Archipelago Regency ( Salawati Island and West Waigeo) and Malalayang Coast, Manado. Explore survey method was applied for sampling and samples was taken using SCUBA equipment in $1-5 \mathrm{~m}$ depth. Collected samples was put into plastic bags then transferred to Marine Biology laboratory FPIK Unsrat. Samples were indentified and documented. This study found four (4) species coraline algae Mastophora rosea from West Waigeo, Amphiroa rigida and Galaxaura rugosa from Salawati Island and Peyssonnelia caulifera from Malalayang Beach.

Keywords: Identification, Description, Coraline Alga, Raja Ampat, Malalayang Coast

Alga koralin merupakan kelompok alga laut (seaweed) yang diklasifikasikan kedalam Divisi Rhodophyta, Kelas Florideophyceae, Ordo Cryptonemiales, Famili Corallinaceae. Secara morfologi (external appearance) kelompok famili ini terbagi atas 2 bagian, yaitu: alga koralin bersegmen (articulated/geniculated Coralline Algae) dan alga koralin tidak bersegmen (nonarticulated/nongeniculated Coralline Algae). Tujuan penelitian ini dilakukan untuk mengidentifikasi jenis alga koralin dan mendeskripsikan morfologi alga koralin. Pengambilan sampel dilakukan di Pulau Salawati, Waigeo Barat Kepulauan Raja Ampat dan Pantai Malalayang Kota Manado. Pengambilan sampel dilakukan dengan bantuan peralatan SCUBA dan diambil pada kedalaman 1-5 meter dengan menggunakan metode survey jelajah. Setiap alga koralin yang di ambil dimasukan ke dalam plastik sampel. Sampel alga koralin di bawah ke Laboratorium Biologi Kelautan FPIK UNSRAT. Selanjutnya, setiap alga diidentifikasi, dicatat dan didokumentasi menggunakan kamera. Penelitian ini berhasil mengidentifikasi berjumlah 4 spesies alga koralin. Keempat spesies tersebut yaitu 1 Mastophora rosea dari Waigeo Barat, 2 dari Pulau Salawati Amphiroa rigida dan Galaxaura rugosa, dan 1 dari Pantai Malalayang Peyssonnelia caulifera.

Kata Kunci : Identifikasi, Deskripsi, Alga Koralin, Raja Ampat, Pantai Malalayang

\section{PENDAHULUAN}

Alga adalah tanaman non-vaskuler yang melakukan fotosintesis, memiliki klorofil a, serta memiliki sistem reproduksi yang sederhana (Dawes 1981). Kelompok alga terbagi atas 2 bagian, yaitu alga makro dan alga mikro. Alga hijau-biru (Cyanophyta) termasuk dalam kelompok alga mikro, sedangkan alga makro terdiri atas 3 divisi, yaitu: alga merah (Rhodophyta), alga hijau (Chlorophyta) dan alga coklat (Phaeophyta). 
Menurut Johansen (1981), alga koralin merupakan kelompok alga laut (seaweed) yang diklasifikasikan ke dalam Divisi Rhodophyta, Kelas Florideophyceae, Ordo Cryptonemiales, Famili Corallinaceae. Ciri-ciri kelompok ini memiliki pigmen klorofil a dan $\mathrm{d}, \alpha$ dan $\beta$ karoten, phyceorythrin, bersifat parasit, bereproduksi dengan spora (tetraspora dan karpospora), serta memiliki 3 fase dalam siklus hidupnya (gametofit, karposporofit, tetrasporofit). Secara morfologi (external appearance) kelompok famili ini terbagi atas 2 bagian, yaitu: alga koralin bersegmen (articulated/geniculated Coralline Algae) dan alga koralin tidak bersegmen (non-articulated/ nongeniculated Coralline Algae). Alga koralin bersegmen memiliki tiga subfamili, yaitu: Corallinoideae, Amphiroideae, dan Metagoniolithoideae. Sedangkan alga koralin tak bersegmen terdiri atas empat subfamili, yaitu: Lithophylloideae, Mastophoroideae, Melobesioideae, dan Schmitzielloideae.

Alga koralin sangat melimpah di seluruh rangkaian ekosistem terumbu karang dan menarik bagi para peneliti untuk mempelajari karakteristik 2 morfologinya (Aguirre dkk. 2001). Alga koralin yang dikelompokkan berdasarkan perbedaan morfologi bertujuan untuk menghadirkan suatu gambaran bentuk pertumbuhan yang telah digunakan lebih dari 200 tahun yang lalu oleh Linnaeus untuk mengklasifikasi dan mengidentifikasi genera, spesies bahkan intraspesifik taksa dari alga koralin tidak bersegmen (Adey dkk. 1982). Penelitian ini bertujuan untuk mengidentifikasi jenis alga koralin dan mendeskripsikan jenis.

\section{METODE PENELITIAN}

Lokasi Penelitian dilakukan di Pulau Salawati, Waigeo Barat Kepaulaun Raja Ampat dan Pantai Malalayang Kota Manado. Penelitian di lakukan selama 4 bulan.

Pengambilan sampel dilakukan dengan metode survey jelajah. Sampel yang ditemukan di buat dalam bentuk Herbarium lalu di identifikasi. Sampel diletekan pada kaca preparat kemudian di potong dengan silet dengan ukuran yang

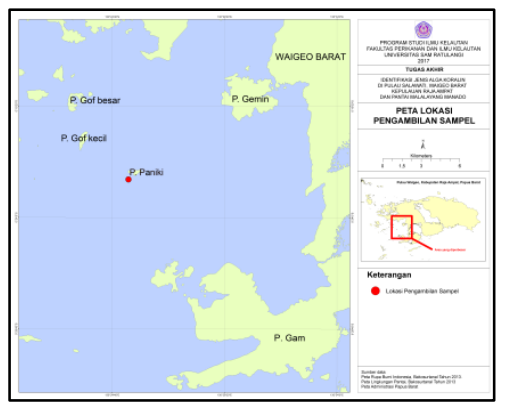

Gambar 1. Pulau Salawati

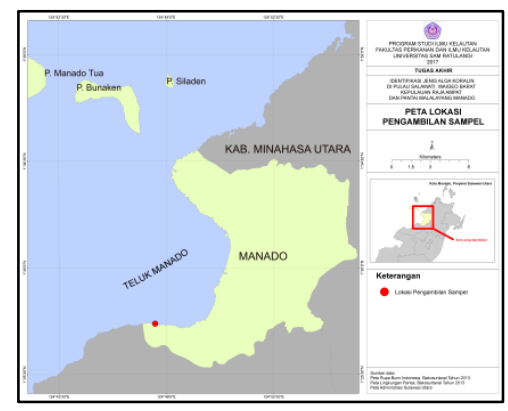

Gambar 2. Waigeo Barat

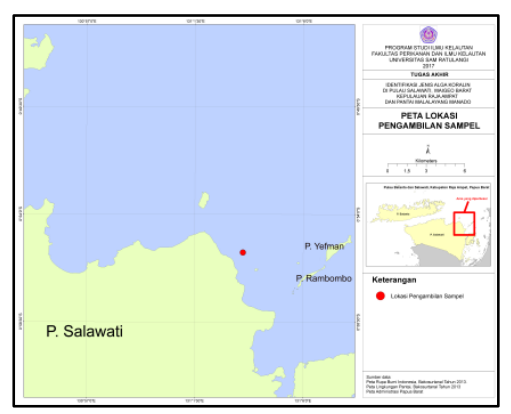

Gambar 3. Pantai Malalayang

lebih kecil secara melintang. Pada potongan talus ditahan dengan pingset agar mendapatkan hasil yang baik. Sampel yang di potong ditetesi dengan larutan anilin blue agar sel dapat dilihat dengan jelas kemudian diletakkan pada mikroskop.

\section{HASIL PENELITIAN}

Pengambilan sampel dilakukan di tiga lokasi, yaitu Waigeo Barat $\left(0^{\circ} 22^{\prime} 24.39\right.$ LS dan $130^{\circ} 25^{\prime} 19.51 \mathrm{BT}$ ), Pulau Salawati

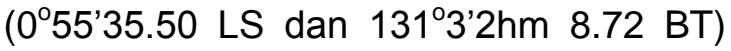
Kepulauan Raja Ampat dan Pantai Malalayang $\left(01^{\circ} 27^{\prime} 39.13 \quad \mathrm{LU}\right.$ dan $124^{\circ} 47^{\prime} 31.84$ BT) Kota Manado. Jenisjenis alga koralin yang diidentifikasi dan 
Tabel 1. Klasifikasi Alga Koralin

\begin{tabular}{|c|c|c|c|c|c|c|}
\hline No & Divisi & Kelas & Ordo & Famili & Genera & Spesies \\
\hline & Rhodophyta & Rhodophyceae & Corallinales & Corallinaceae & Amphiroa & $\begin{array}{l}\text { Amphiroa rigida } \\
\text { Lamouroux }\end{array}$ \\
\hline & Rhodophyta & Rhodophyceae & Nemalales & Galaxauraceae & Galaxaura & $\begin{array}{l}\text { Galaxaura } \\
\text { rugosa (Ellis and } \\
\text { Salonder) } \\
\text { Lamouroux }\end{array}$ \\
\hline & Rhodophyta & Rhodophyceae & Corallinales & Corallinaceae & Mastophora & $\begin{array}{l}\text { Mastophora } \\
\text { rosea (C. } \\
\text { Agardh) } \\
\text { Setchell }\end{array}$ \\
\hline & Rhodophyta & Florideophyceae & Peyssonneliales & Peyssonneliaceae & Peyssonnelia & $\begin{array}{l}\text { Peyssonnelia } \\
\text { caulifera } \\
\text { Okamura }\end{array}$ \\
\hline
\end{tabular}

dideskripsikan sebanyak 4 spesies (Tabel 1).

\section{Deskripsi Alga Koralin}

\section{Amphiroa rigida Lamouroux}

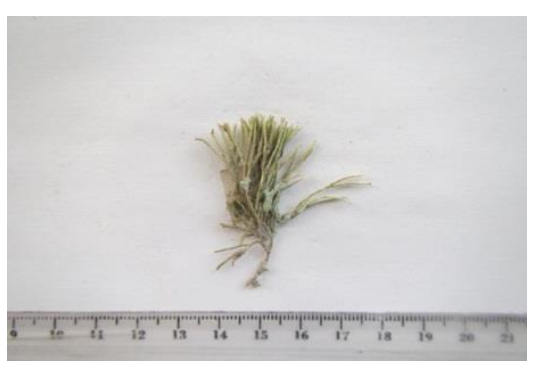

Talus silindris tegak, membentuk koloni warna merah dengan holdfast berupa cakram kecil, percabangan tidak beraturan, sangat berkapur. Tinggi talus 5 $\mathrm{cm}$. terdapat genikula yang mehubungkan segmen-segmen interginikula. Habitat alga ini yaitu tumbuh dan menempel pada dasar pasir atau pada substrat rataan terumbu.
Galaxaura rugosa (Ellis and Salonder)
Lamouroux

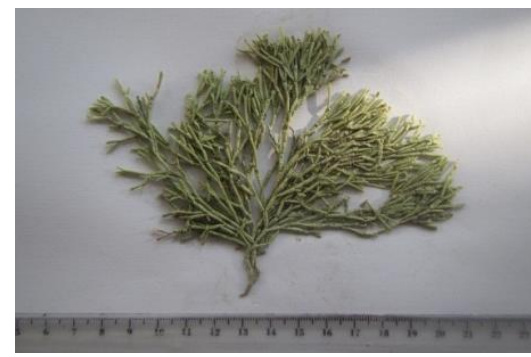

Talus lebat, kaku, kompak, tinggi talus 5-7 cm, percabang dikotomis. Cabang berbentuk silinder, mempunyai holdfast pada substrat. Habitat di bebatuan karang.

Mastophora rosea (C. Agardh) Setchell

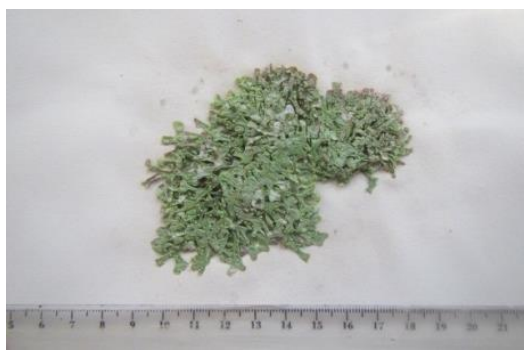


Talus berbentuk gepeng, berwarna hijau muda kemerahan, tidak beraturan dan biasanya dalam bentuk koloni. Tinggi total talus 1,3-2,1 cm. Bagian permukaan talus tidak rata dan agak kaku ketika di herbarium dan sudah kering, terdapat bintil-bintil bulat yang menutupi sebagian permukaan talus. Pada umumnya hidup di substrat karang dan menyebar di daerah intertidal.

\section{Peyssonnelia caulifera Okamura}

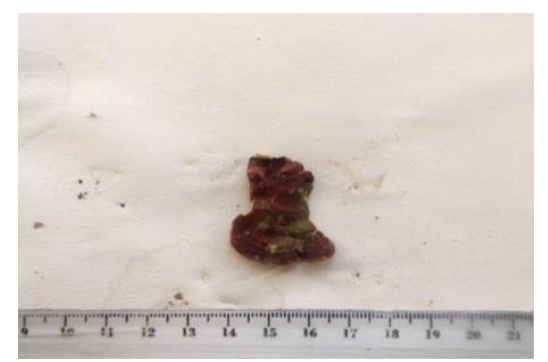

Berbentuk daun pipi dan melebar 3-4 cm. Panjang dan luas hampir sama. Sangat tebal karna menempel dengan karang. Warna kemerahan, agak memudar saat kering. Habitat pada bebatuan di daerah intertidal.

\section{KESIMPULAN}

Dari hasil identifikasi secara keseluruhan di peroleh 4 spesies yaitu : (1) Mastophora rosea dari Waigeo Barat (2) Amphiroa rigida dari Pulau Salawati (3) Galxaura rigida dari Pulau Salawati (4) Peyssonelia caulifera dari Pantai Malalayang. Secara deskripsi ada perbedaan dari setiap spesies yaitu, dari bentuk talus yang berbeda-beda, bentuk ukuran dari setiap spesies dan dari keempat spesies tersebut terdapat 3 alga koralin yang bersegemen yaitu Mastophora rosea, Amphiroa rigida, Galxaura rigida dan 1 alga koralin yang tidak bersegmen yaitu Peyssonelia caulifera.

\section{DAFTAR PUSTAKA}

Adey, W.H., Townsend, R.A., dan Boykins, W.T., 1982. The Crustose coralline algae (Rhodophyta: Corallinaceae) of the Hawaiian
Islands. Smithsonian Contributions to Marine Science. , 1-74.

Aguirre J., Baceta J.I., Braga J.C., dan Pujalte V., 2001. Danian Coralline Red Algae from the BasqueCantabrian Region, W. Pyrenean Basin, North Spain. Abstracts of the 4th Regional Symposium on Fossil Algae Cluj, Rumania.

Dawes, C.J., 1981. Marine Botany. John Wiley \& Sons, Inc University of South Florida. USA. p 628.

Johansen, H.W., 1981. Coralline Algae, A First Synthesis. CRC Press, Inc.Boca Raton, Florida-United States. p 238. 